\title{
Response assessment in metastatic melanoma treated with ipilimumab and bevacizumab: CT tumor size and density as markers for response and outcome
}

Mizuki Nishino ${ }^{1 *}$, Anita Giobbie-Hurder ${ }^{2}$, Nikhil H Ramaiya ${ }^{1+}$ and F Stephen Hodi ${ }^{3+}$

\begin{abstract}
Background: Investigate the tumor diameter and density changes in advanced melanoma patients treated with ipilimumab plus bevacizumab, compare response rates based on different response criteria, and study association between these measures and survival.

Methods: Twenty-one advanced melanoma patients with 59 measurable lesions treated in a phase 1 trial of ipilimumab plus bevacizumab were retrospectively studied. Tumor diameter and density were measured on baseline and first follow-up CT. Responses were assigned using RECIST, MASS and Choi criteria. Diameter and density measures and responses by these criteria were studied for the association with survival.

Results: Twenty-three (39\%) lesions and 7 (33\%) patients met the Choi density criteria for response ( $\geq 15 \%$ density decrease) at the first follow-up. The response rates were 14\% (3/21,95\% CI: 3-36\%) by RECIST and MASS, and 52\% (11/21, 95\% Cl: 30-74\%) by Choi criteria, when both size and density criteria were used. Larger baseline tumor diameter was significantly associated with shorter progression-free survival (PFS) and overall survival (OS) (log-rank $p=0.001$ and 0.003 ; respectively). Diameter or density changes, or responses by RECIST, MASS or Choi criteria at the first follow-up, were not associated with PFS or OS.

Conclusion: Tumor density decrease meeting Choi criteria was noted in one-third of advanced melanoma patients at the first follow-up scan during ipilimumab plus bevacizumab therapy. While larger baseline tumor diameter was strongly associated with shorter survival, changes of diameter or density, or responses by three criteria did not predict survival. The role of density changes in evaluating response during ipilimumab and bevacizumab therapy for advanced melanoma remains to be further established.
\end{abstract}

Keywords: Melanoma, Immunotherapy, Anti-angiogenic therapy, Tumor response, Density, RECIST

\section{Background}

Recent advances in the understanding of the mechanisms of tumor immunomodulation and the clinical application of immunotherapeutic agents have brought a new era of cancer immunotherapy [1,2]. Clinical benefit of immunotherapeutic agents is best demonstrated in metastatic melanoma, in which ipilimumab, an anti-

\footnotetext{
* Correspondence: Mizuki_Nishino@DFCI.HARVARD.EDU

${ }^{\dagger}$ Equal contributors

'Department of Radiology, Brigham and Women's Hospital and Dana-Farber Cancer Institute, 450 Brookline Avenue, Boston, MA 02215, USA

Full list of author information is available at the end of the article
}

CTLA-4 antibody, has shown significant improvement in overall survival (OS) [3]. Ipilimumab has shown clinical activity in other solid tumors such as lung cancer and prostate cancer [4-6]. Newer agents, including antiPD-1 (programmed cell death protein 1) antibodies and anti-PD-L1 (programmed cell death protein ligand-1) antibodies, have also shown marked activity against melanoma and other advanced cancers [7-10], further expanding the role of cancer immunotherapy.

In efforts to further enhance the efficacy of these agents that block immune checkpoint, predictive markers of response to immunotherapy are being actively investigated. 
The immunosuppressive microenvironment of the tumor may restrict the anti-tumor activity of cancer treatment, which may be further enhanced by the abnormal tumor vasculature [11]. Vascular endothelial growth factor (VEGF) is a potent angiogenic factor that regulates angiogenesis and at the same time increases proliferation, migration, and metastasis of melanoma. VEGF is also known to inhibit dendritic cell maturation and T-cell responses [12,13], thus suppressing antitumor immune responses. Serum level of VEGF-A prior to treatment was shown to be associated with clinical response and OS in advanced melanoma patients treated with ipilimumab which confirmed a generalizable mechanism to immunotherapy resistance via angiogenic cytokines including VEGF [14]. There was no correlation between changes in VEGF levels following treatment and clinical outcome [14]. The finding led to the phase 1 study of the combination therapy of ipilimumab and bevacizumab (anti-angiogenic agent which inhibits VEGF-A). The trial demonstrated a disease-control rate (defined as the proportion of patients with best response of complete response, partial response, or stable disease at any time while on study) of $67.4 \%$. The median survival of this phase 1 study was 25.1 months, which was longer compared to 10.1 months in advanced melanoma patients treated with ipilimumab alone in a prior phase 3 study [3], providing a basis for further pursuit of the combination of immunotherapy and anti-angiogenic therapy [15].

Tumors treated with immunotherapeutic agents are known to demonstrate unique response patterns on imaging, because these agents exert anti-cancer activity by blocking intrinsic immune inhibition by cancer and causing $\mathrm{T}$ cell infiltration of the tumors [1-3]. These immunerelated response patterns may not be captured by conventional tumor response criteria, such as RECIST and WHO criteria [16,17]. Immune-related response criteria (irRC) have been proposed to better describe treatment results of immunotherapy, and the efforts have been made to further optimize the methods for immune-related response assessment $[18,19]$.

Tumors treated with anti-angiogenic therapy may benefit from incorporation of tumor density change on computed tomography (CT) measured in Hounsfield Unit (HU), as a marker for devascularization and necrosis in response to therapy [20-22]. Furthermore, diameter changes smaller than the conventional threshold may represent response in these patients. Choi criteria defined response as $\geq 10 \%$ diameter decrease or $\geq 15 \%$ decrease in density in patients with gastrointestinal stromal tumors treated with imatinib, which correlate with disease-specific survival [20-22]. In 40 GIST patients treated with imatinib, 32 patients met the Choi response criteria of either a more than $10 \%$ decrease in maximum diameter or a more than $15 \%$ decrease in tumor density at 2 months after treatment, and these 32 patients had significantly longer time to tumor progression compared to the remaining 8 patients without Choi response [22]. Choi criteria have been used in renal cell carcinomas (RCC) and hepatomas treated with sunitinib that blocks multiple receptor tyrosine kinases including VEGF receptors [23,24]. Among 26 advanced HCC patients, 17 patients $(65.4 \%)$ were responders by Choi criteria and had a significantly longer TTP (7.5 months) compared with nonresponders (4.8 months; $\mathrm{HR}=0.33, \mathrm{P}=0.0182$ ).

In RCC treated with anti-angiogenic therapy, another modified criteria called MASS (morphology, attenuation, size, and structure) criteria has been proposed, and define response as $\geq 20 \%$ diameter decrease, or $\geq 40 \mathrm{HU}$ density decrease, or marked central necrosis in predominantly solid enhancing lesion(s) [16,25]. MASS criteria were recently studied in metastatic melanoma treated with bevacizumab with or without interferon, and shown to strongly predict progression-free survival (PFS) and OS [26]. Given these prior observations and the recent promising phase 1 trial results, it is worthwhile to study tumor diameter and density changes, in addition to conventional tumor diameter changes, during the combined therapy of ipilimumab and bevacizumab in capturing tumor response and predicting outcome.

The purpose of the study is to investigate the tumor diameter and density changes on CT in advanced melanoma patients treated with ipilimumab plus bevacizumab, compare response rates at the first follow-up based on different response criteria incorporating tumor diameters and density, and study association between these measures and survival.

\section{Results and discussion}

A total of 59 measurable lesions in 21 patients (median and mean number of lesions per patient: 2 and 2.8, respectively; range: $1-8$ ) were included. Table 1 summarizes demographics and disease characteristics of the 21 patients. There were 15 lung lesions, 14 peritoneal or retroperitoneal lesions, 11 liver, 9 subcutaneous, 5 nodes and 5 adrenal lesions.

\section{Lesion-based analysis}

The median baseline diameter and density for the 59 lesions were $25 \mathrm{~mm}$ (range: 10-55) and 44.9 HU (range: 7.2-80.1). The median changes at the first follow-up were 10.7\% (range: -64.7 to 102.6 ) for diameter, and $-9.7 \%$ (range: -56.6 to 177.2 ) and $-2.7 \mathrm{HU}$ (range: -31.0 to 28.3 ) for CT density. Figure 1 demonstrates the percent changes of diameter and density in 59 lesions. Table 2 summarizes the response by diameter and density of these lesions. No lesions met the density criteria by MASS, while 23 (39\%) lesions met the Choi density criteria ( $\geq 15 \%$ density decrease). When diameter and density changes were 
Table 1 Summary of patient characteristics and tumor measurements

\begin{tabular}{|c|c|c|}
\hline \multicolumn{3}{|c|}{ Baseline demographics and disease characteristics } \\
\hline \multirow[t]{2}{*}{ Gender } & Male & $14(66.7)$ \\
\hline & Female & $7(33.3)$ \\
\hline Age (years) & Median [Range] & $53[25-68]$ \\
\hline \multirow[t]{2}{*}{ Tumor stage } & IV & $20(95.2)$ \\
\hline & III Unresectable & $1(4.8)$ \\
\hline \multirow[t]{4}{*}{ Doses of agents } & $\begin{array}{l}\text { Ipi: } 10 \mathrm{mg} / \mathrm{kg} \\
\text { Bev: } 15 \mathrm{mg} / \mathrm{kg}\end{array}$ & $8(38.1)$ \\
\hline & $\begin{array}{l}\text { Ipi: } 10 \mathrm{mg} / \mathrm{kg} \text {, } \\
\text { Bev: } 7.5 \mathrm{mg} / \mathrm{kg}\end{array}$ & $5(23.8)$ \\
\hline & $\begin{array}{l}\text { Ipi: } 3 \text { mg/kg, } \\
\text { Bev: } 15 \mathrm{mg} / \mathrm{kg}\end{array}$ & $2(9.5)$ \\
\hline & $\begin{array}{l}\text { Ipi: } 3 \mathrm{mg} / \mathrm{kg} \text {, } \\
\text { Bev: } 7.5 \mathrm{mg} / \mathrm{kg}\end{array}$ & $6(28.6)$ \\
\hline \multirow[t]{2}{*}{ Baseline sum diameter $(\mathrm{mm})$} & Median [Range] & 38 [10-178] \\
\hline & Mean $[S D]$ & $55.1[43.9]$ \\
\hline \multirow[t]{2}{*}{ Baseline average density (HU) } & Median [Range] & $43.2[8.0-69.2]$ \\
\hline & Mean [SD] & $43.4[16.2]$ \\
\hline \multicolumn{3}{|c|}{ Changes from the baseline measurements } \\
\hline \multirow{2}{*}{$\begin{array}{l}\text { Absolute diameter change at } \\
1^{\text {st }} \text { follow-up }(\mathrm{mm})\end{array}$} & Median [Range] & $0[-21.0-56]$ \\
\hline & Mean $[S D]$ & $5.5[18.0]$ \\
\hline \multirow{2}{*}{$\begin{array}{l}\text { Proportional diameter change } \\
\text { at } 1^{\text {st }} \text { follow-up (\%) }\end{array}$} & Median [Range] & $0[-64.7-85.7]$ \\
\hline & Mean $[S D]$ & $3.6[34.4]$ \\
\hline \multirow{2}{*}{$\begin{array}{l}\text { Absolute density change at } \\
1^{\text {st }} \text { follow-up (HU) }\end{array}$} & Median [Range] & $-4.3[-24.3-18.5]$ \\
\hline & Mean [SD] & $-3.1[10.8]$ \\
\hline \multirow{2}{*}{$\begin{array}{l}\text { Proportional density change } \\
\text { at } 1^{\text {st }} \text { follow-up (\%) }\end{array}$} & Median [Range] & $-8.4[-44.3-49.1]$ \\
\hline & Mean [SD] & $-3.1[24.5]$ \\
\hline
\end{tabular}

The numbers represent the number of patients with percentage in parentheses, unless otherwise specified. Ipi = ipilimumab, Bev = bevacizumab.

combined, 4 lesions (7\%) responded by RECIST, 9 lesions (15\%) responded by MASS, and 29 lesions (49\%) responded by Choi criteria.

\section{Patient-based analysis}

The baseline sum diameter and average density and their changes on the first follow-up scans are summarized in Table 1. Figure 2 demonstrates the percent changes of diameter and density in 21 patients. No patients met the density criteria by MASS, while 7 (33\%, [95\% CI: $15-57 \%]$ ) patients met density response criteria by Choi (Table 3). When diameter and density changes are combined, 3 patients (14\%, [95\% CI: 3-36\%]) responded by RECIST and MASS, and additional 8 patients responded by Choi criteria, resulting in a total of 11 Choi responders (52\%, [95\% CI: 30-74\%]) (Figure 3). None of the patients with response by these criteria developed new lesions at the time of the first follow-up scan. In 2 out of
13 patients with 2 or more lesions, discrepant CT density changes among lesions of the same patient was noted, with some lesions showing $>15 \%$ density decrease and other lesions showing marked (i.e., >30\%) increase in density. Both patients met the response by Choi density criteria when the average density was used to represent the overall change.

\section{Association with survival}

At the time of analysis, 14 patients (67\%) had progressed and 6 patients (29\%) had died. The median follow-up was 29.7 months.

\section{Baseline diameter/density vs. survival}

Baseline diameter was significantly associated with PFS and OS, with larger baseline diameters having poorer outcomes. When patients were dichotomized at the median baseline diameter, which was $38 \mathrm{~mm}$ in this cohort, median PFS for patients with baseline diameter $\leq 38 \mathrm{~mm}$ was 27.5 months compared with 4.1 months for those with diameter $>38 \mathrm{~mm}$ (HR (high vs. low) 5.3, [95\% CI 1.6 to 18 ], $\mathrm{p}=0.007)$. Each $5 \mathrm{~mm}$ increase in baseline diameter increased the hazard of a PFS event by $14 \%$ (HR: 1.14, [95\% CI 1.05-1.23], $\mathrm{p}=0.001$ ) (Figure 4). Median OS was not reached for patients with diameter $\leq 38 \mathrm{~mm}$ vs. 12.6 months for those with diameter $>38 \mathrm{~mm}$. No deaths occurred in patients with baseline diameters at or below the median. Each $5 \mathrm{~mm}$ increase in baseline diameter increase the hazard of death by $18 \%(\mathrm{HR}=1.18,[95 \% \mathrm{CI}$ : 1.06-1.31], $\mathrm{p}=0.003$ ) (Figure 5).

Baseline density was not associated with PFS (HR (high vs. low) 1.3, [95\% CI 0.4 to 3.6], $\mathrm{p}=0.68$ ) or with OS (HR (high vs. low) $0.7,95 \%$ CI 0.1 to $4.0, \mathrm{p}=0.71$ ).

Diameter/density changes on the $1^{\text {st }}$ follow-up and outcome Among the total of 21 patients, 5 patients had progressed at the $1^{\text {st }}$ follow-up scan while 16 patients had not progressed. These 16 patients were assessed using a conditional landmark analysis at 11 weeks (the median time to the first scan in this group: 11.3 weeks; range: 11-12 weeks). The continuous Cox model, although limited by the small number of patients $(\mathrm{N}=16)$, suggested that the percent increase of tumor diameter on the $1^{\text {st }}$ follow-up scan result in shorter PFS and OS. Each $5 \%$ increase in diameter results in a $13 \%$ increase in the hazard of a subsequent PFS event $(\mathrm{HR}=1.13$, [95\% CI: 0.94-1.36], $\mathrm{p}=0.18$ ). Each 1\% increase in percent change in diameter increased the risk of death 1.5 times $(\mathrm{HR}=1.49$, [95\% CI: 0.8-3.0], $\mathrm{p}=0.25)$. Neither the percent nor absolute change in CT density influenced subsequent PFS (HR for each 5\% density increase: 0.997 [95\% CI: 0.88-1.14], p = 0.96; HR for each $1 \mathrm{HU}$ density increase: 0.999 [95\% CI: 0.94-1.06], $\mathrm{p}=0.98$ ) or OS (HR for each 5\% density increase:1.08 [95\% CI: 0.82-1.44], 


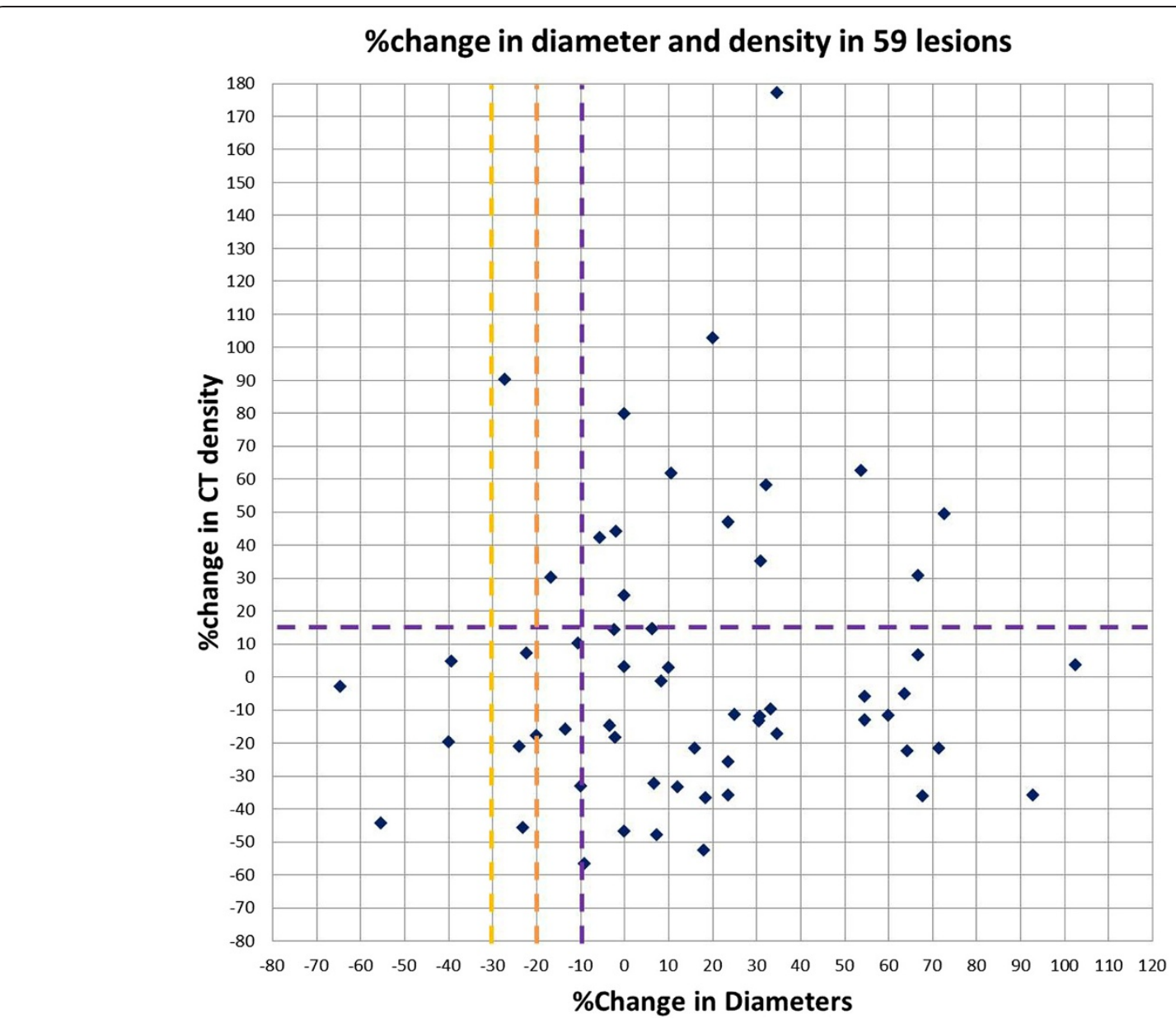

Figure 1 Scatter plot of the percent changes of the tumor diameter and density on the first follow-up CT compared to the baseline CT in 59 lesions. The cut-off values for response are indicated by the yellow dashed line for RECIST ( $\geq 30 \%$ diameter decrease), by the orange dashed line for MASS ( $\geq 20 \%$ diameter decrease), and by the purple dashed lines for Choi ( $\geq 10 \%$ diameter decrease or $\geq 15 \%$ density decrease) criteria. No lesions met the density response criteria by MASS.

Table 2 The number of lesions meeting each response criteria

\begin{tabular}{ll}
\hline Criteria & $\begin{array}{l}\text { Number of } \\
\text { lesions (\%) }\end{array}$ \\
\hline Diameter changes & \\
RECIST ( $\geq 30 \%$ decrease) & $4(7 \%)$ \\
MASS ( $\geq 20 \%$ decrease) & $9(15 \%)$ \\
Choi ( $\geq 10 \%$ decrease) & $13(22 \%)$ \\
Density changes & \\
MASS ( $\geq 40 \mathrm{HU}$ decrease or marked central necrosis) & $0(0 \%)$ \\
Choi $(\geq 15 \%$ decrease) & $23(39 \%)$ \\
Combined diameter and density criteria & \\
$\quad \begin{array}{l}\text { MASS ( } \geq 20 \% \text { diameter decrease, } \geq 40 \mathrm{HU} \\
\text { density decrease, or marked central necrosis) }\end{array}$ & $9(15 \%)$ \\
$\begin{array}{l}\text { Choi ( }(\geq 10 \% \text { diameter decrease of } \geq 15 \% \\
\text { density decrease) }\end{array}$ & $29(49 \%)$ \\
\hline
\end{tabular}

$\mathrm{p}=0.57$; HR for each $1 \mathrm{HU}$ density increase: $1.05[95 \%$ CI: 0.91-1.22], $\mathrm{p}=0.51$ ).

\section{Response by RECIST, MASS and Choi criteria vs survival}

RECIST and MASS criteria yielded the same 3 responders and were summarized together. No significant PFS or OS differences were observed between RECIST/MASS responders vs. non-responders ( $\mathrm{p}=$ $0.45,0.46$, respectively). There was no significant PFS or OS difference between Choi responders vs. nonresponders $(\mathrm{p}=0.90,0.94$, respectively).

\section{Measurement variability}

The intra-observer agreement was high for both diameter and density measurements, with CCC of 0.9865 and 0.9967 , respectively. The $95 \%$ limits of agreement were $(-22.5,15.5 \%)$ for the sum diameter, and were $(-5.8$, 


\section{Diameter and Density Changes in 21 patients}

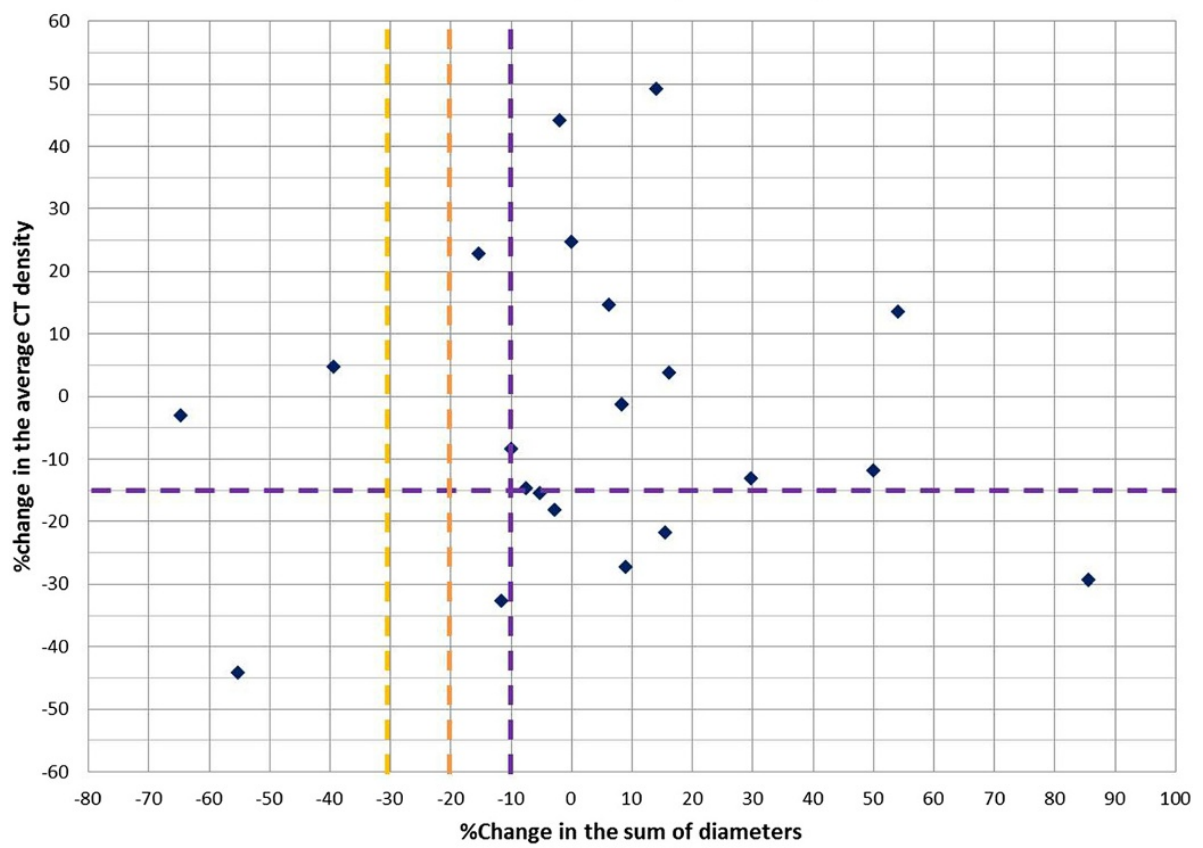

Figure 2 Scatter plot of the percent changes of the tumor diameter and density on the first follow-up CT compared to the baseline CT in 21 patients. The cut-off values for response are indicated by the yellow dashed line for RECIST ( $\geq 30 \%$ diameter decrease), by the orange dashed line for MASS ( $\geq 20 \%$ diameter decrease), and by the purple dashed lines for Choi ( $\geq 10 \%$ diameter decrease or $\geq 15 \%$ density decrease) criteria. No patients met the density response criteria by MASS.

$6.5 \%)$ and $(-2.3,2.7 \mathrm{HU})$ for the average density (Table 3 , Figure 6A-B). The inter-observer agreement was high for both diameter and density measurements, with CCC of 0.9774 and 0.9934 , respectively. The $95 \%$ limits of agreement were $(-27.1,26.7 \%)$ for the sum diameter, and were $(-12.0,8.3 \%)$ and $(-4.1,2.8 \mathrm{HU})$ for the average density (Table 4, Figure 6C-D).

Table 3 The number of patients meeting each response criteria

\begin{tabular}{|c|c|}
\hline Criteria & $\begin{array}{l}\text { Number of patients } \\
(\%[95 \% \mathrm{Cl}])\end{array}$ \\
\hline \multicolumn{2}{|l|}{ Diameter changes } \\
\hline RECIST ( $\geq 30 \%$ decrease) & $3(14 \%[3-36 \%])$ \\
\hline MASS ( $\geq 20 \%$ decrease) & $3(14 \%[3-36 \%])$ \\
\hline Choi ( $\geq 10 \%$ decrease) & $6(28 \%[11-52 \%])$ \\
\hline \multicolumn{2}{|l|}{ Density changes } \\
\hline $\begin{array}{l}\text { MASS ( } \geq 40 \mathrm{HU} \text { decrease or marked } \\
\text { central necrosis) }\end{array}$ & $0(0 \%)$ \\
\hline Choi ( $\geq 15 \%$ decrease) & 7 (33\% [15-57\%]) \\
\hline \multicolumn{2}{|l|}{ Combined diameter and density criteria } \\
\hline $\begin{array}{l}\text { MASS ( } \geq 20 \% \text { diameter decrease, } \geq 40 \mathrm{HU} \\
\text { density decrease, or marked central necrosis) }\end{array}$ & $3(14 \%[3-36 \%])$ \\
\hline $\begin{array}{l}\text { Choi ( } \geq 10 \% \text { diameter decrease of } \geq 15 \% \\
\text { density decrease) }\end{array}$ & $11(52 \%[30-74 \%])$ \\
\hline
\end{tabular}

\section{Discussion}

The present study demonstrated that $\geq 15 \%$ tumor density decrease by Choi criteria was noted in one third of the advanced melanoma patients treated with ipilimumab plus bevacizumab combination therapy at their first follow-up CT. Larger baseline diameter was strongly associated with shorter PFS and OS, however, diameter and density changes or responses by RECIST, MASS, or Choi criteria at the first follow-up were not associated

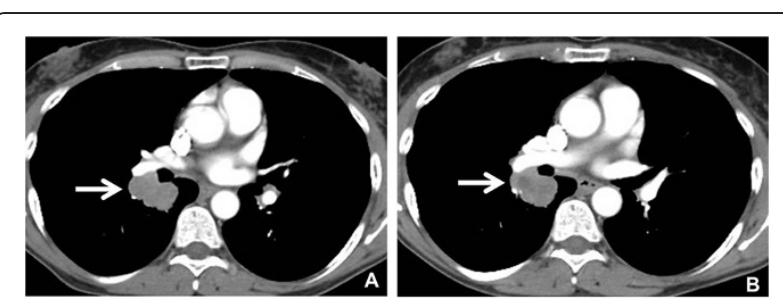

Figure 3 A 61-year-old male with metastatic melanoma. Contrast-enhanced CT scan of the chest at baseline (A) demonstrate a lobulated right lower lobe mass measuring $37 \mathrm{~mm}$ and $54.3 \mathrm{HU}$ (A, arrow). The follow-up scan (B) at 11.4 weeks of ipilimumab and bevacizumab therapy demonstrated the lesion measuring $36 \mathrm{~mm}$ and $44.4 \mathrm{HU}(\mathrm{B}$, arrow). While the percent decrease of diameter was only $2 \%$, CT density decreased by $18 \%$ comparing to baseline, meeting the Choi response criteria. 


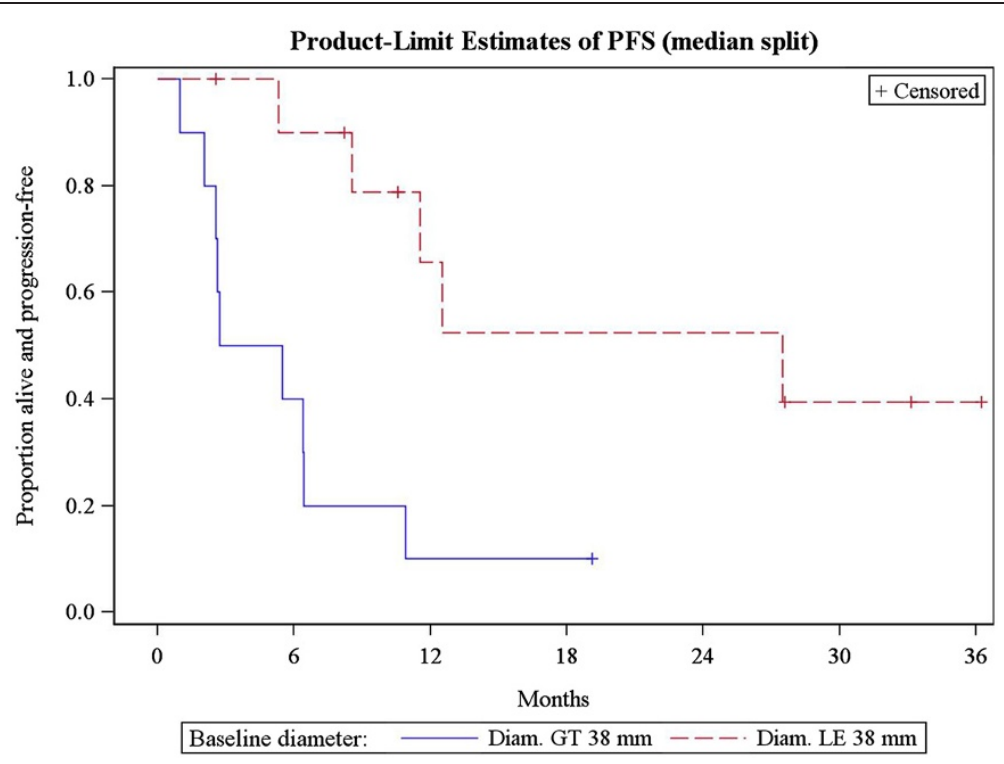

Figure 4 Progression-free survival in patients dichotomized using the median baseline diameter (38 $\mathrm{mm}$ ).

with survival. While density decrease is a relatively common phenomenon in advanced melanoma treated with ipilimumab plus bevacizumab, further studies are needed to define its role in assessing anti-cancer activity and therapeutic benefit of the agents and to identify objective imaging marker that can predict outcome during the combined immunotherapy and anti-angiogenic therapy.

The degree of diameter and density changes in our cohort were similar to the previous report by Gray et al. in their study of metastatic melanoma patients treated with bevacizumab with or without interferon, which reported the average of $2 \%$ diameter change and $-7 \%$ density change [26]. No lesions or patients in our study met the density response criteria by MASS, indicating that such a marked decrease in density is a rare phenomenon among melanoma patients receiving ipilimumab plus bevacizumab. Our observation is similar with the report by Gary et al., which had only 1 out of 118 lesions showing

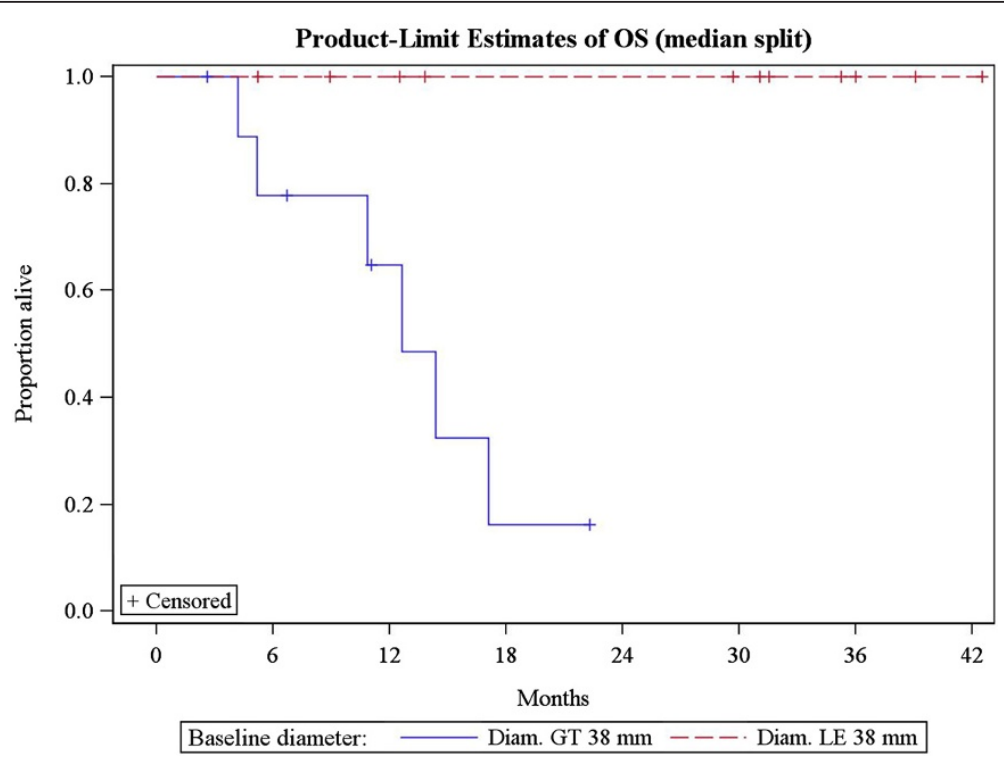

Figure 5 Overall survival in patients dichotomized using the median baseline diameter $(38 \mathrm{~mm})$. 


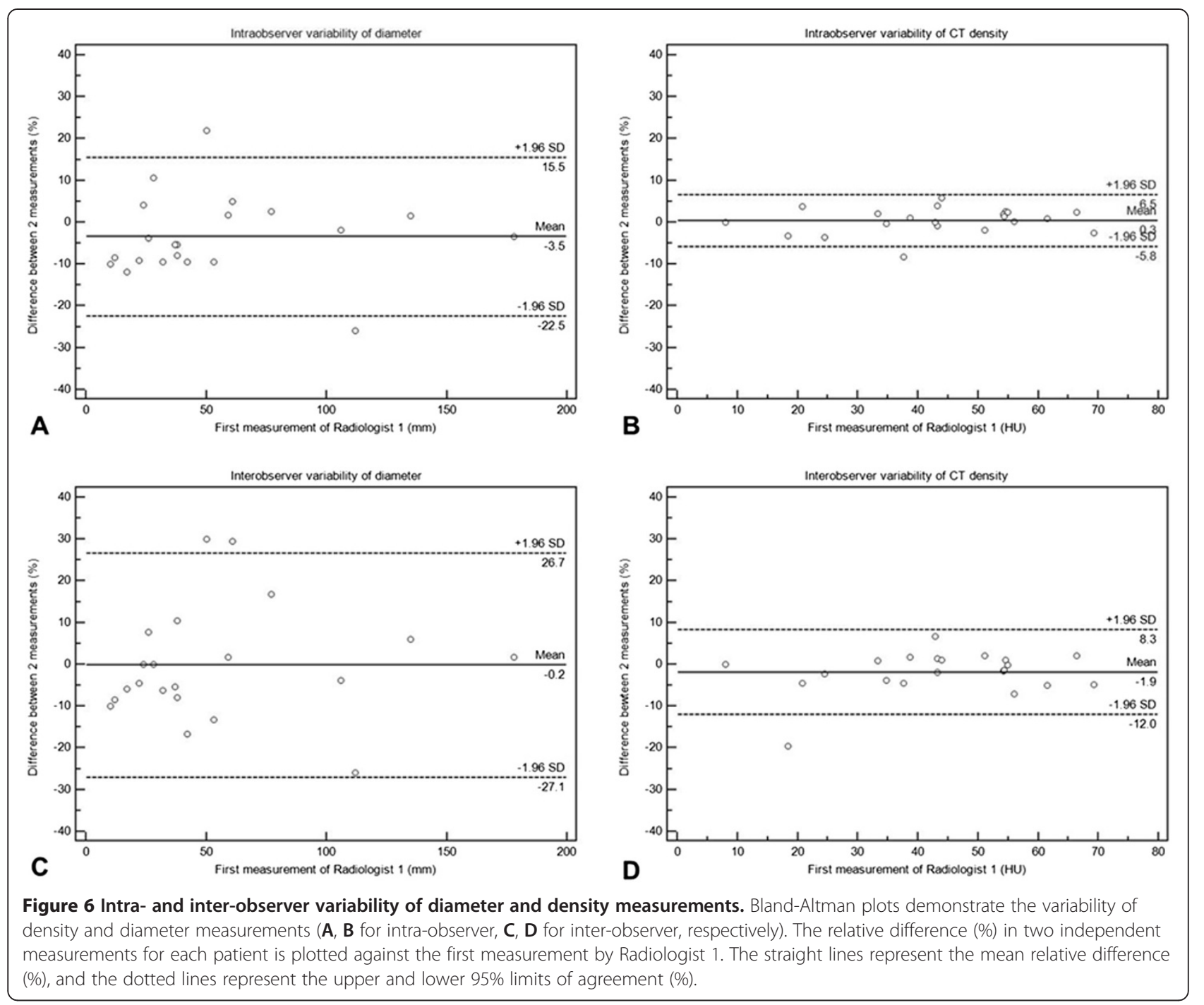

marked central necrosis [26]. Density decrease $\geq 40 \mathrm{HU}$ were more frequent in their cohort (6/118 lesions (5\%) and 6/44 patients (14\%)), which could be due to the different therapeutic regimen in the prior report where the majority $(39 / 44,89 \%)$ of the patients received interferon in addition to bevacizumab [26].

When three different criteria for response were used for 59 lesions, the lesion-based response rate was 7\% (4/ 59) by RECIST, $15 \%$ (9/59) by MASS, and $49 \%(29 / 59)$ by Choi criteria. For the patient-based analysis, the response rate was $14 \%(3 / 21)$ by RECIST and MASS, and $52 \%(11 / 21)$ by Choi (4 patients responding by diameter decrease, 5 patients by density decrease and 2 patients meeting both diameter and density criteria). The increase in response rate by applying the Choi density criteria indicates that CT density decrease may be a sequela of the anti-cancer activity of ipilimumab and bevacizumab therapy. Similar increase of response rate was noted in the prior study, in which response rates at the first follow-up CT were 7\% (3/44) for RECIST, 14\% (6/44) for MASS, and 34\% (15/44) for Choi criteria [26].

Heterogeneous changes of CT density within same patient were noted in 15\% (2/13) among the patients with more than 1 lesion, while overall assessment using the average density met Choi density response criteria in both patients. Tumoral heterogeneity is an important issue in assessing response to targeted therapy [27,28], and the quantitative imaging approach to address this issue remain to be established. The current standard approach including the one used in the present study relies on a certain number of representative lesions to demonstrate systemic tumor burden changes, which is associated with inherent limitations. Further studies are needed to assess the frequency and impact of heterogeneous density changes during therapy.

While different definitions of response can give rise to different rates of response, these modified definitions of response need to be validated by studying association 
Table 4 Intra- and inter-observer variability of measurements in 21 patients

\begin{tabular}{llll}
\hline Intra-observer variability & CCC [95\% Cl] & $\begin{array}{l}\text { Mean relative } \\
\text { difference }\end{array}$ & $\begin{array}{l}\text { 95\% limits of } \\
\text { agreement }\end{array}$ \\
Diameter & $0.9865[0.9691-0.9941]$ & $-3.5(\%)$ & $-22.5,15.5(\%)$ \\
CT density & $0.9967[0.9921-0.9987]$ & $0.3(\%)$ & $-5.8,6.5(\%)$ \\
& & $0.2(\mathrm{HU})$ & $-2.3,2.7(\mathrm{HU})$ \\
Inter-observer variability & & \\
Diameter & $0.9774[0.9459-0.9907]$ & $-0.2(\%)$ & $-27.1,26.7(\%)$ \\
CT density & $0.9934[0.9841-0.9973]$ & $-1.9(\%)$ & $-12.0,8.3(\%)$ \\
& & $-0.6(\mathrm{HU})$ & $-4.1,2.8(\mathrm{HU})$ \\
\hline
\end{tabular}

with outcome. The alternate definitions are of great clinical significance if they can differentiate responders with survival benefit more accurately than the conventional definitions. In our study, baseline diameter was the only significant predictor of PFS and OS; other measures including baseline density and diameter/density changes at the first follow-up were not significantly associated with survival. Univariate Cox models suggested that the percent increase of tumor diameter on the $1^{\text {st }}$ followup scan may result in shorter PFS and OS; however, these results need to be viewed cautiously given the small number of patients and events. None of the three response criteria (RECIST, MASS and Choi criteria) differentiated patients with longer survival at the first follow-up scan, indicating the need to further studies to identify objective markers that can predict survival at the early course of therapy to guide therapeutic decisions. Given the unique mechanism of anticancer activity of ipilimumab, the density changes in the present cohort may be at least in part due to infiltration of tumor by immune cells. Future investigations may also focus on the biological background of the density changes, as well as the comparison of tumor density among cohorts receiving ipilimumab alone, bevacizumab alone and the combination.

Tumor density changes have been extensively studied in the context of anti-angiogenic therapy to improve strategy for tumor response evaluation [20,21,23,25]. Recently, immune-related responses have been investigated based on tumor size changes [17-19,29]. The present study represents the first attempt to further optimize the existing tumor response criteria specifically for combined therapy using anti-angiogenic agents and immunomodulating agents, which will be more frequently used in treatment of advanced cancer in the near future.

Gary et al. reported that MASS response at the first follow-up strongly predicted PFS and OS [26]. The different results between 2 studies may be due to the different regimen. Our study also had only 3 MASS responders. High baseline serum lactate dehydrogenase (LDH) level was also associated with survival in their study [26]. In our cohort, stratification according to elevated baseline LDH was not possible since there were only 2 patients with elevated levels. The association between baseline measures and survival was not mentioned in the prior study [26].

Our study demonstrated high intra- and interobserver agreement for both diameter and density measurements. Based on the $95 \%$ limits of agreement, $15 \%$ density decrease was beyond the intra- and interobserver measurement variability in our cohort. However, $10 \%$ diameter decrease was within the $95 \%$ limits of intra- and inter-observer agreement, alerting the possibility of misclassification by measurement error when applying Choi criteria [30]. Intra-observer variability was narrower than inter-observer variability for both diameter and density, indicating the measurements by same reader on baseline and follow-up scans help to decrease misclassification. Given nearly two thirds of Choi responders $(7 / 11,64 \%)$ responded by density criteria regardless of the diameter changes, it may worthwhile to see if adding the density criteria to the conventional RECIST diameter criteria ( $\geq 30 \%$ decrease) may better identify patients with therapeutic benefit while avoiding misclassification.

The limitations of the present study include retrospective design and a small number of patients treated at a single institution. Due to the design of the phase 1 trial, the doses of ipilimumab and bevacizumab varied among the patients in the small cohort. The study reports the initial observations of tumor diameter and density changes during ipilimumab and bevacizumab therapy, which needs to be studied further in larger cohorts. The study also focused on the tumor changes at the first follow-up study; the role of serial measurements of diameter and density in defining progression and treatment failure remain to be investigated. The serial CT density measurements may also help to identify cases with delayed response to immunotherapy. In addition, the serial measurements will provide an opportunity to assess the impact of immune-related response assessment incorporating new lesions into the measurements in comparison with the conventional RECIST based approach in the assessment of CT tumor density.

\section{Conclusions}

In conclusion, tumor density decrease meeting Choi criteria ( $\geq 15 \%$ decrease) was relatively common during ipilimumab plus bevacizumab combination therapy for advanced melanoma, noted in one-third of the patients. Larger baseline tumor diameter was strongly associated with shorter 
survival; however, diameter and density changes at the first follow-up or responses by RECIST, MASS or Choi criteria were not associated with survival in these patients. The role of density changes in evaluating anti-cancer activity and therapeutic benefit of these agents remain to be further studied in a larger cohort.

\section{Methods}

\section{Patients}

The study included 21 advanced melanoma patients (14 males, 7 females; median age: 53 years, age range: 2568) treated in a phase 1 trial of ipilimumab plus bevacizumab at the Dana-Farber Cancer Institute [15]. All patients had baseline CT and at least one follow-up CT using iodinated intravenous contrast agents, and had at least one measurable lesion $(\geq 10 \mathrm{~mm}$ longest diameters for non-nodal lesions, $\geq 15 \mathrm{~mm}$ in short axis for lymph nodes [31,32]). Patients were treated with ipilimumab with four doses at 3-week intervals and then every 12 weeks, and bevacizumab every 3 weeks [15]. The protocol was approved by the Institutional Review Board of the Dana-Farber Cancer Institute, and all patients provided written informed consent. The clinical trial results including survival and adverse events of the entire multicenter cohort have been previously reported [15].

\section{CT tumor measurements}

The standard clinical protocol for body CT at the DanaFarber Cancer Institute used a 64-row MDCT scanner (Aquilion 64; Toshiba America Medical Systems, CA). Patients are scanned in the supine position from the cranial to caudal direction from the clavicles to the pubic symphysis at end-inspiration. During the study, $100 \mathrm{~mL}$ of iopromid (Ultravist 300, $300 \mathrm{mg}$ iodine/mL; Bayer HealthCare Pharmaceuticals Inc. Wayne, NJ) is injected intravenously at a rate of $3 \mathrm{~mL} / \mathrm{sec}$, with a scan delay of 30 seconds for chest and 70 seconds for abdomen (portal venous phase). Axial images (5 mm thickness) were reconstructed and transferred to a Picture Archiving
Communication System (PACS) workstation (Centricity, General Electric, Milwaukee,WI).

Baseline CT scans prior to initiation of therapy (median time between baseline scan and initiation of therapy: 1.0 week; range: $0.3-3.0$ weeks) were retrospectively reviewed by a board-certified radiologist with expertise in oncologic imaging (M.N.). All measurable lesions in each patient were selected, regardless of the number of lesions in total or per organ, in order to evaluate heterogeneity among lesions within the same patient [28]. The exception included 2 patients with innumerable $(>20)$ lesions in one organ (lung in one patient and liver in other), in whom the largest 5 lesions within the organ (lung/liver) were selected, in addition to all the measurable lesions in other organs.

The diameters ( $\mathrm{mm}$; the longest diameters for non-nodal lesions and short axis for nodes) and density (HU) were measured for all lesions on contrast-enhanced CT images on baseline scans and on the first follow-up scans (median time to the first follow-up scan: 11.3 weeks). Diameters were measured using a caliper-type measurement tool on PACS workstation [33]. The CT attenuation was measured using an oval region of interest covering the maximum area of each lesion excluding the surrounding structures [34]. Three lesions (2 lung and 1 subcutaneous lesions) demonstrated $<0 \mathrm{HU}$ at baseline due to partial volume effects, which were ineligible for the study and excluded.

\section{Diameter and density changes on follow-up}

The percent changes of diameter and CT density were calculated on the follow-up scan in reference to the baseline $[35,36]$. For CT density, the absolute change (HU) was also calculated. For lesion-based analysis, the diameter and density measurements of each lesion were used. For patient-based analysis, the sum of the diameters and the average of CT density were used to represent baseline and follow-up measurements [20-22,36]; for those who had $>5$ lesions in total and $>2$ lesions per organ, up to 5 largest lesions in total and up to 2 largest

Table 5 Summary of tumor response assessment and definitions for RECIST, Choi and MASS criteria

\begin{tabular}{|c|c|c|c|}
\hline & RECIST & MASS & Choi \\
\hline \multirow[t]{3}{*}{ Measurements and lesion evaluations } & Diameter $^{* 1}$ & Diameter & Diameter \\
\hline & & $\mathrm{CT}$ attenuation $(\mathrm{HU})$ & $\mathrm{CT}$ attenuation $(\mathrm{HU})$ \\
\hline & & Marked central necrosis ${ }^{* 2}$ & \\
\hline Response criteria ${ }^{* 3}$ & $\geq 30 \%$ diameter decrease & $\begin{array}{l}\geq 20 \% \text { diameter decrease, } \geq 40 \mathrm{HU} \text { decrease, } \\
\text { or marked central necrosis }\end{array}$ & $\begin{array}{l}\geq 10 \% \text { diameter decrease, } \\
\text { or } \geq 15 \% \text { density decrease }\end{array}$ \\
\hline
\end{tabular}

*1: The longest diameters for non-nodal lesions and short axis for nodes were used according to RECIST1.1 [31]. This was applied to size measurement for Choi and MASS criteria in the present study.

* 2 : Marked central necrosis is defined as $>50 \%$ of the enhancing central portion of a predominantly solid enhancing mass subjectively changing to near fluid attenuation (necrosis) after treatment [25].

*3: The sum of the diameters of all target lesions and the average of CT density measured in HU are used to assess response, comparing the values on the follow-up scan during therapy in reference to the values on the baseline pretherapy scan. 
lesions per organ were chosen according to RECIST1.1, based on the baseline measurements.

Response was assigned for each lesion and each patient, based on RECIST ( $\geq 30 \%$ decrease in diameter) $[31,32,37]$, MASS $(\geq 20 \%$ decrease in diameter or $\geq 40 \mathrm{HU}$ decrease in density or marked central necrosis) [25,38] and Choi criteria ( $\geq 10 \%$ decrease in diameter or $\geq 15 \%$ decrease in density) [20-22] (Table 5).

\section{Measurement variability}

To assess measurement variability, two board-certified radiologists (Radiologist 1: M.N. and Radiologist 2: N.H.R.) independently measured the diameter and density of all lesions on baseline scans, without access to other radiologist's measurements, as described previously $[18,19,36,39]$. Radiologist 1 performed measurements twice with one week interval, without access to the prior measurements.

\section{Statistical analysis}

Descriptive methods were used to summarize patient demographic and disease characteristics. Measurements on a continuous scale were summarized using mean, median, standard deviation, and range. Categorical characteristics were summarized using percentages and 95\% exact binomial confidence intervals. The distributions of progression-free survival (PFS) and overall survival (OS) were assessed using the product-limit method of KaplanMeier, with 95\% confidence intervals (CI) estimated using $\log [-\log$ (outcome) $]$ methodology. To investigate the association between baseline diameter/density and outcome, PFS and OS were compared between 2 groups dichotomized at the median baseline diameter $(38 \mathrm{~mm})$ or density (43.2 HU). Cox proportional hazards models were used to estimate hazard ratios (HRs) and 95\% confidence intervals; p-values are based on the Wald chi-squared statistic. In addition, univariate Cox proportional hazard models were used to estimate the effects on outcome of $5 \mathrm{~mm}$ increments in baseline diameter or $5 \mathrm{HU}$ increments in baseline density. Eleven-week conditional landmark analyses were used to evaluate differences in outcome according to response or changes in diameter or density.

All p-values were two-sided, with statistical significance defined as $\mathrm{P}<0.05$. There were no corrections for multiple comparisons.

Intra- and inter-observer variability were assessed using concordance correlation coefficients (CCCs), mean relative difference and 95\% limits of agreement. CCCs are products of a measure of precision and a measure of accuracy where $C C C$ value 1 indicates perfect agreement and -1 indicates perfect reversed agreement [40]. The mean relative difference (\%) between the two measurements is defined as $100^{*}\left[\mathrm{M}_{1}-\mathrm{M}_{2}\right] / \mathrm{M}_{1}\left(\mathrm{M}_{1}=\right.$ measurement $1, M_{2}=$ measurement 2). Bland-Altman plots were used to visually demonstrate the variability between the two measurements $[36,39,41]$. Two measurements of Radiologist 1 were used to assess intra-observer variability. The first measurement of Radiologist 1 and the measurement by Radiologist 2 were used to evaluate inter-observer variability.

Both survival and measurement variability were assessed according to patient-based analyses, using the sum diameters and the average density for each patient.

\section{Abbreviations}

OS: Overall survival; PD-1: Program death-1; VEGF: Vascular endothelial growth factor; RECIST: Response evaluation criteria in solid tumors;

WHO: World Health Organization; irRC: Immune-related response criteria; CT: Computed tomography; HU: Hounsfield unit; RCC: Renal cell carcinomas; MASS: Morphology, attenuation, size, and structure; PFS: Progression-free survival; LDH: Lactate dehydrogenase; MDCT: Multi-row detector CT; PACS: Picture Archiving Communication System; Cl: Confidence intervals; HR: Hazard ratios; CCC: Concordance correlation coefficient; GT: Greater than; LE: Less than or equal to.

\section{Competing interest}

Nikhil H. Ramaiya, MD, Anita Giobbie-Hurder, MS: Nothing to disclose. Mizuki Nishino, MD: Dr. Nishino has served as a consultant to Bristol-Myers Squibb.

F. Stephen Hodi, MD: Dr. Hodi has served as a non-paid consultant to BristolMyers Squibb and has received clinical trial support from Bristol-Myers Squibb.

\section{Authors' contributions}

MN: Conception and study design, data acquisition and review of the images and measurements, statistical analysis and interpretation of data, drafting and revising the manuscript. NHR: Conception and study design, data acquisition and review of the images and measurements, interpretation of data, drafting and revising the manuscript. GH: Data acquisition, statistical analysis and interpretation of data, drafting and revising the manuscript. FSH: Conception and study design, data acquisition, interpretation of data, drafting and revising the manuscript. All authors read and approved the final manuscript.

\section{Acknowledgement}

The investigator, MN, was supported by 1K23CA157631 (NCI).

\section{Author details}

'Department of Radiology, Brigham and Women's Hospital and Dana-Farber Cancer Institute, 450 Brookline Avenue, Boston, MA 02215, USA. ²Department of Biostatistics and Computational Biology, Dana-Farber Cancer Institute, 450 Brookline Avenue, Boston, MA 02215, USA. '3 Department of Medical Oncology and Department of Medicine, Dana-Farber Cancer Institute and Brigham and Women's Hospital, 450 Brookline Avenue, Boston, MA 02215, USA.

Received: 15 September 2014 Accepted: 28 October 2014

Published online: 18 November 2014

\section{References}

1. Hodi FS, Mihm MC, Soiffer RJ, Haluska FG, Butler M, Seiden MV, Davis T, Henry-Spires R, MacRae S, Willman A, Padera R, Jaklitsch MT, Shankar S, Chen TC, Korman A, Allison JP, Dranoff G: Biologic activity of cytotoxic $t$ lymphocyte-associated antigen 4 antibody blockade in previously vaccinated metastatic melanoma and ovarian carcinoma patients. Proc Natl Acad Sci U S A 2003, 100:4712-4717.

2. Hodi FS, Oble DA, Drappatz J, Velazquez EF, Ramaiya N, Ramakrishna N, Day AL, Kruse A, Mac Rae S, Hoos A, Mihm M: Ctla-4 blockade with ipilimumab induces significant clinical benefit in a female with melanoma metastases to the cns. Nat Clin Pract Oncol 2008, 5:557-561.

3. Hodi FS, O'Day SJ, McDermott DF, Weber RW, Sosman JA, Haanen JB, Gonzalez R, Robert C, Schadendorf D, Hassel JC, Akerley W, van den Eertwegh AJ, Lutzky J, Lorigan P, Vaubel JM, Linette GP, Hogg D, Ottensmeier CH, Lebbe C, Peschel C, Quirt I, Clark JI, Wolchok JD, Weber JS, 
Tian J, Yellin MJ, Nichol GM, Hoos A, Urba WJ: Improved survival with ipilimumab in patients with metastatic melanoma. N Engl J Med 2010, 363:711-723.

4. Lynch TJ, Bondarenko I, Luft A, Serwatowski P, Barlesi F, Chacko R, Sebastian M, Neal J, Lu H, Cuillerot JM, Reck M: Ipilimumab in combination with paclitaxel and carboplatin as first-line treatment in stage iiib/iv non-small-cell lung cancer: results from a randomized, double-blind, multicenter phase ii study. J Clin Oncol 2012, 30:2046-2054.

5. Reck M, Bondarenko I, Luft A, Serwatowski P, Barlesi F, Chacko R, Sebastian M, Lu H, Cuillerot JM, Lynch TJ: Ipilimumab in combination with paclitaxel and carboplatin as first-line therapy in extensive-disease-small-cell lung cancer: results from a randomized, double-blind, multicenter phase 2 trial. Ann Oncol 2013, 24:75-83.

6. Kwon ED, Drake CG, Scher HI, Fizazi K, Bossi A, van den Eertwegh AJ, Krainer M, Houede N, Santos R, Mahammedi H, Ng S, Maio M, Franke FA, Sundar S, Agarwal N, Bergman AM, Ciuleanu TE, Korbenfeld E, Sengelov L, Hansen S, Logothetis C, Beer TM, McHenry MB, Gagnier P, Liu D, Gerritsen WR: Ipilimumab versus placebo after radiotherapy in patients with metastatic castration-resistant prostate cancer that had progressed after docetaxel chemotherapy (ca184-043): a multicentre, randomised, double-blind, phase 3 trial. Lancet Oncol 2014, 15:700-712.

7. Topalian SL, Hodi FS, Brahmer JR, Gettinger SN, Smith DC, McDermott DF, Powderly JD, Carvajal RD, Sosman JA, Atkins MB, Leming PD, Spigel DR, Antonia SJ, Horn L, Drake CG, Pardoll DM, Chen L, Sharfman WH, Anders RA, Taube JM, McMiller TL, Xu H, Korman AJ, Jure-Kunkel M, Agrawal S, McDonald D, Kollia GD, Gupta A, Wigginton JM, Sznol M: Safety, activity, and immune correlates of anti-pd-1 antibody in cancer. N Engl J Med 2012, 366:2443-2454.

8. Wolchok JD, Kluger H, Callahan MK, Postow MA, Rizvi NA, Lesokhin AM, Segal NH, Ariyan CE, Gordon RA, Reed K, Burke MM, Caldwell A, Kronenberg SA, Agunwamba BU, Zhang X, Lowy I, Inzunza HD, Feely W, Horak CE, Hong Q, Korman AJ, Wigginton JM, Gupta A, Sznol M: Nivolumab plus ipilimumab in advanced melanoma. N Engl J Med 2013, 369:122-133.

9. Topalian SL, Sznol M, McDermott DF, Kluger HM, Carvajal RD, Sharfman WH, Brahmer JR, Lawrence DP, Atkins MB, Powderly JD, Leming PD, Lipson EJ, Puzanov I, Smith DC, Taube JM, Wigginton JM, Kollia GD, Gupta A, Pardoll DM, Sosman JA, Hodi FS: Survival, durable tumor remission, and long-term safety in patients with advanced melanoma receiving nivolumab. J Clin Oncol 2014, 32:1020-1030.

10. Brahmer JR, Tykodi SS, Chow LQ, Hwu WJ, Topalian SL, Hwu P, Drake CG, Camacho LH, Kauh J, Odunsi K, Pitot HC, Hamid O, Bhatia S, Martins R, Eaton K, Chen S, Salay TM, Alaparthy S, Grosso JF, Korman AJ, Parker SM, Agrawal S, Goldberg SM, Pardoll DM, Gupta A, Wigginton JM: Safety and activity of anti-pd-I1 antibody in patients with advanced cancer. N Engl J Med 2012, 366:2455-2465.

11. Huang Y, Yuan J, Righi E, Kamoun WS, Ancukiewicz M, Nezivar J, Santosuosso M, Martin JD, Martin MR, Vianello F, Leblanc P, Munn LL, Huang P, Duda DG, Fukumura D, Jain RK, Poznansky MC: Vascular normalizing doses of antiangiogenic treatment reprogram the immunosuppressive tumor microenvironment and enhance immunotherapy. Proc Natl Acad Sci U S A 2012, 109:17561-17566.

12. Oyama T, Ran S, Ishida T, Nadaf S, Kerr L, Carbone DP, Gabrilovich DI: Vascular endothelial growth factor affects dendritic cell maturation through the inhibition of nuclear factor-kappa $b$ activation in hemopoietic progenitor cells. J Immunol 1998, 160:1224-1232.

13. Dikov MM, Ohm JE, Ray N, Tchekneva EE, Burlison J, Moghanaki D, Nadaf S, Carbone DP: Differential roles of vascular endothelial growth factor receptors 1 and 2 in dendritic cell differentiation. J Immunol 2005, 174:215-222.

14. Yuan J, Zhou J, Dong Z, Tandon S, Kuk D, Panageas KS, Wong P, Wu X, Naidoo J, Page DB, Wolchok JD, Hodi FS: Pretreatment serum vegf is associated with clinical response and overall survival in advanced melanoma patients treated with ipilimumab. Cancer Immunol Res 2014, 2:127-132.

15. Hodi FS, Lawrence D, Lezcano C, Wu X, Zhou J, Sasada T, Zeng W, GiobbieHurder A, Atkins MB, Ibrahim N, Friedlander P, Flaherty KT, Murphy GF, Rodig S, Velazquez EF, Mihm MC Jr, Russell S, DiPiro PJ, Yap JT, Ramaiya N, Van den Abbeele AD, Gargano M, McDermott D: Bevacizumab plus ipilimumab in patients with metastatic melanoma. Cancer Immunol Res 2014, 2:632-642

16. Nishino M, Jagannathan JP, Krajewski KM, O'Regan K, Hatabu H, Shapiro G, Ramaiya NH: Personalized tumor response assessment in the era of molecular medicine: cancer-specific and therapy-specific response criteria to complement pitfalls of recist. AJR Am J Roentgenol 2012, 198:737-745.
17. Wolchok JD, Hoos A, O'Day S, Weber JS, Hamid O, Lebbe C, Maio M, Binder M, Bohnsack O, Nichol G, Humphrey R, Hodi FS: Guidelines for the evaluation of immune therapy activity in solid tumors: immune-related response criteria. Clin Cancer Res 2009, 15:7412-7420.

18. Nishino M, Gargano M, Suda M, Ramaiya NH, Hodi FS: Optimizing immunerelated tumor response assessment: does reducing the number of lesions impact response assessment in melanoma patients treated with ipilimumab? J Immunother Cancer 2014, 2:17.

19. Nishino M, Giobbie-Hurder A, Gargano M, Suda M, Ramaiya NH, Hodi FS: Developing a common language for tumor response to immunotherapy: immune-related response criteria using unidimensional measurements. Clin Cancer Res 2013, 19:3936-3943.

20. Benjamin RS, Choi H, Macapinlac HA, Burgess MA, Patel SR, Chen LL, Podoloff DA, Charnsangavej C: We should desist using recist, at least in gist. J Clin Oncol 2007, 25:1760-1764.

21. Choi H, Charnsangavej C, de Castro FS, Tamm EP, Benjamin RS, Johnson MM, Macapinlac HA, Podoloff DA: Ct evaluation of the response of gastrointestinal stromal tumors after imatinib mesylate treatment: a quantitative analysis correlated with fdg pet findings. AJR Am J Roentgenol 2004, 183:1619-1628.

22. Choi H, Charnsangavej C, Faria SC, Macapinlac HA, Burgess MA, Patel SR, Chen LL, Podoloff DA, Benjamin RS: Correlation of computed tomography and positron emission tomography in patients with metastatic gastrointestinal stromal tumor treated at a single institution with imatinib mesylate: proposal of new computed tomography response criteria. J Clin Oncol 2007, 25:1753-1759.

23. Faivre S, Zappa M, Vilgrain V, Boucher E, Douillard JY, Lim HY, Kim JS, Im SA, Kang YK, Bouattour M, Dokmak S, Dreyer C, Sablin MP, Serrate C, Cheng AL, Lanzalone S, Lin X, Lechuga MJ, Raymond E: Changes in tumor density in patients with advanced hepatocellular carcinoma treated with sunitinib. Clin Cancer Res 2011, 17:4504-4512.

24. van der Veldt AA, Meijerink MR, van den Eertwegh AJ, Haanen JB, Boven E: Choi response criteria for early prediction of clinical outcome in patients with metastatic renal cell cancer treated with sunitinib. Br J Cancer 2010, 102:803-809.

25. Smith AD, Shah SN, Rini Bl, Lieber ML, Remer EM: Morphology, attenuation, size, and structure (mass) criteria: assessing response and predicting clinical outcome in metastatic renal cell carcinoma on antiangiogenic targeted therapy. AJR Am J Roentgenol 2010, 194:1470-1478.

26. Gray MR, Martin del Campo S, Zhang X, Zhang H, Souza FF, Carson WE 3rd, Smith AD: Metastatic melanoma: lactate dehydrogenase levels and ct imaging findings of tumor devascularization allow accurate prediction of survival in patients treated with bevacizumab. Radiology 2014, 270:425-434.

27. Nishino M, Hatabu H, Johnson BE, McLoud TC: State of the art: response assessment in lung cancer in the era of genomic medicine. Radiology 2014, 271:6-27.

28. Menzies AM, Haydu LE, Carlino MS, Azer MW, Carr PJ, Kefford RF, Long GV: Inter- and intra-patient heterogeneity of response and progression to targeted therapy in metastatic melanoma. PLoS One 2014, 9:e85004.

29. Tirkes T, Hollar MA, Tann M, Kohli MD, Akisik F, Sandrasegaran K: Response criteria in oncologic imaging: review of traditional and new criteria. Radiographics 2013, 33:1323-1341.

30. Erasmus JJ, Gladish GW, Broemeling L, Sabloff BS, Truong MT, Herbst RS, Munden RF: Interobserver and intraobserver variability in measurement of non-small-cell carcinoma lung lesions: implications for assessment of tumor response. J Clin Oncol 2003, 21:2574-2582.

31. Eisenhauer EA, Therasse P, Bogaerts J, Schwartz LH, Sargent D, Ford R, Dancey J, Arbuck S, Gwyther S, Mooney M, Rubinstein L, Shankar L, Dodd L, Kaplan R, Lacombe D, Verweij J: New response evaluation criteria in solid tumours: revised recist guideline (version 1.1). Eur J Cancer 2009, 45:228-247.

32. Nishino M, Jagannathan JP, Ramaiya NH, Van den Abbeele AD: Revised recist guideline version 1.1: What oncologists want to know and what radiologists need to know? AJR Am J Roentgenol 2010, 195:281-289.

33. Nishino M, Cardarella S, Jackman DM, Ramaiya NH, Rabin MS, Hatabu H, Janne PA, Johnson BE: Recist 1.1 in nsclc patients with egfr mutations treated with egfr tyrosine kinase inhibitors: comparison with recist 1.0. AJR Am J Roentgenol 2013, 201:W64-W71.

34. Araki T, Sholl LM, Gerbaudo VH, Hatabu H, Nishino M: Imaging characteristics of pathologically proven thymic hyperplasia: identifying features that can differentiate true from lymphoid hyperplasia. AJR Am J Roentgenol 2014, 202:471-478. 
35. Nishino M, Dahlberg SE, Cardarella S, Jackman DM, Rabin MS, Hatabu H, Janne PA, Johnson BE: Tumor volume decrease at 8 weeks is associated with longer survival in egfr-mutant advanced non-small-cell lung cancer patients treated with egfr tki. J Thorac Oncol 2013, 8:1059-1068.

36. Krajewski KM, Nishino M, Franchetti Y, Ramaiya NH, Van den Abbeele AD, Choueiri TK: Intraobserver and interobserver variability in computed tomography size and attenuation measurements in patients with renal cell carcinoma receiving antiangiogenic therapy: implications for alternative response criteria. Cancer 2014, 120:711-721.

37. Therasse P, Arbuck SG, Eisenhauer EA, Wanders J, Kaplan RS, Rubinstein L, Verweij J, Van Glabbeke M, van Oosterom AT, Christian MC, Gwyther SG: New guidelines to evaluate the response to treatment in solid tumors. European organization for research and treatment of cancer, National Cancer Institute of the United States, National Cancer Institute of Canada. J Natl Cancer Inst 2000, 92:205-216.

38. Smith $A D$, Lieber ML, Shah SN: Assessing tumor response and detecting recurrence in metastatic renal cell carcinoma on targeted therapy: importance of size and attenuation on contrast-enhanced ct. AJR Am J Roentgenol 2010, 194:157-165.

39. Nishino M, Guo M, Jackman DM, DiPiro PJ, Yap JT, Ho TK, Hatabu H, Janne $P A$, Van den Abbeele AD, Johnson BE: Ct tumor volume measurement in advanced non-small-cell lung cancer: performance characteristics of an emerging clinical tool. Acad Radiol 2011, 18:54-62.

40. Lin LI: A concordance correlation coefficient to evaluate reproducibility. Biometrics 1989, 45:255-268.

41. Bland JM, Altman DG: Statistical methods for assessing agreement between two methods of clinical measurement. Lancet 1986, 1:307-310.

doi:10.1186/s40425-014-0040-2

Cite this article as: Nishino et al:: Response assessment in metastatic melanoma treated with ipilimumab and bevacizumab: CT tumor size and density as markers for response and outcome. Journal for

ImmunoTherapy of Cancer 2014 2:40.

\section{Submit your next manuscript to BioMed Central and take full advantage of:}

- Convenient online submission

- Thorough peer review

- No space constraints or color figure charges

- Immediate publication on acceptance

- Inclusion in PubMed, CAS, Scopus and Google Scholar

- Research which is freely available for redistribution 